SITIOS, INTERVENCIONES Y GESTIÓN

\title{
El megalitismo en la ordenación del espacio y la tutela del Patrimonio Histórico de Andalucía
}

Arturo del Pino Ruiz, Dirección General de Bienes Culturales, Consejería de Cultura de la Junta de Andalucía

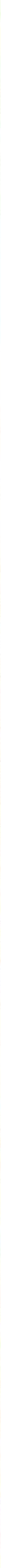


La tutela practicada sobre los bienes megalíticos en Andalucía -en el sentido anglosajón de protection- ha sido muy desigual desde la promulgación de las primeras normativas legales de protección del patrimonio histórico hasta la actualidad. Conviven en el espacio y en el territorio las viejas figuras decimonónicas de salvaguardia, simbolizada en los llamados "monumentos nacionales", con las modernas acciones inmateriales preventivas que tienen por objeto la protección de elementos patrimoniales diacrónicos (VERDUGO SANTOS, 2004) en el territorio. En medio, todo un patrimonio de "grandes piedras" inventariado o desconocido, que reivindica hoy más que nunca técnicas jurídico-administrativas de carácter vinculante y de salvaguardia, a la vez que medidas urgentes de conservación.

Y es que, pese al reforzamiento e inclusión de nuevas tipologías, medidas y figuras de gestión creadas por la neonata Ley 14/2007 de Patrimonio Histórico de Andalucía, los bienes culturales, y en especial los arqueológicos, por su cuantía, dispersión y vulnerabilidad, reclaman otras medidas transversales y prioritarias de protección dentro de las políticas de ordenación del territorio, urbanismo y medio ambiente.

Aunque cada vez son más, como decimos, las tipologías y la clasificación de los bienes culturales que tienen en cuenta el espacio y el territorio como soporte de esos bienes tutelados (Conjuntos Históricos, Sitios Históricos, Zonas Arqueológicas, Lugares de Interés Etnológico e Industrial y las Zonas Patrimoniales; así como sus correspondientes figuras de gestión y administración en la forma de Conjuntos y Parques Culturales, aún por materializar y desarrollar), lo cierto es que el patrimonio arqueológico megalítico no ha sido de los más beneficiados por estas figuras de protección. Con todo, hay que decir que con la actual legislación' y la configuración de la Red de Espacios Culturales de Andalucía (RECA) se prevén sistemas integrados y unitarios formados por ámbitos culturales -en clara referencia a los Conjuntos y Parques Culturales- ubicados en el te- rritorio de la Comunidad, así como aquellos enclaves abiertos al público, como sería la Red de Yacimientos Arqueológicos de Andalucía. En este sentido, se está impulsando ya, por ejemplo, la configuración del Conjunto Dolménico de Antequera (Málaga).

Por otro lado, según se desprende del Sistema de Información del Patrimonio Histórico de Andalucía (SIPHA), como uno de los tradicionales programas de tutela del patrimonio histórico, según el II Plan General de Bienes Culturales de Andalucía (2000), en nuestra Comunidad existirían 448 dólmenes, megalitos, túmulos funerarios y algunos poblados asociados $^{2}$. De éstos, menos de 20 están considerados como Bienes de Interés Cultural bajo la tipología de Zona Arqueológica, entendida como figura de protección espacial. Conjuntos dolménicos, asociados a poblados, como los de Belmez, Fuente Obejuna (Córdoba); Fonelas, Gorafe (Granada); Valverde del Camino, Zalamea la Real (Huelva); Almadén de la Plata, El Castillo de las Guardas (Sevilla); Alhama de Almería, Tabernas (Almería), ... por poner algunos ejemplos representativos de conjuntos dolménicos de primer orden, se encuentran "virtualmente" desprotegidos. Si partimos de la premisa que la protección del patrimonio arqueológico debe basarse en el más completo conocimiento de su existencia, de su amplitud y de su naturaleza; y que los inventarios generales con delimitación del potencial arqueológico son, por tanto, instrumentos esenciales de trabajo para perfilar estrategias de protección de dicho patrimonio ${ }^{3}$, ¿por qué no gozan en la actualidad, los ejemplos citados anteriormente, de las figuras de salvaguardia correspondientes una vez superada la fase del "monumento-isla" como obra de arte?. ¿Acaso hoy en día seguimos sin entender el yacimiento arqueológico dentro de un marco espacial más amplio, como soporte cultural de una sociedad que deja huella histórica en el territorio y en el paisaje?. O por el contrario, ¿son demasiado complejos, administrativamente hablando, los procedimientos de inscripción de estos bienes en el Catálogo General de Patrimonio Histórico Andaluz, como instrumento de tutela de los mismos? 
Entendemos, que el patrimonio histórico, y por su fragilidad, especialmente el arqueológico, hoy por es hoy es más vulnerable que nunca a los grandes procesos de transformación de los usos del suelo, el urbanismo depredador y las grandes infraestructuras públicas o privadas (PINO RUIZ, 2006). En un mundo en el que se están produciendo continuamente cambios de tipo técnico, comercial, financiero y cultural, es indispensable, que los instrumentos de planificación territorial contribuyan al desarrollo sostenible y la preservación de nuestro legado histórico y natural. Hasta el momento, la inclusión del patrimonio histórico dentro de las políticas de planificación del territorio y el urbanismo han sido escasas, permitiéndose incluso procesos de sub/rururbanización en los entornos de los pueblos y ciudades de Andalucía, con un fuerte componente patrimonial, del cual ejemplos no nos faltarían.

Después de treinta años del traspaso de competencias exclusivas del Estado a las Comunidades Autónomas, por mandato constitucional, observamos que dentro de la organización del espacio, en un sentido labasseiano (LABASSE, 1972), el patrimonio histórico, a grandes rasgos,

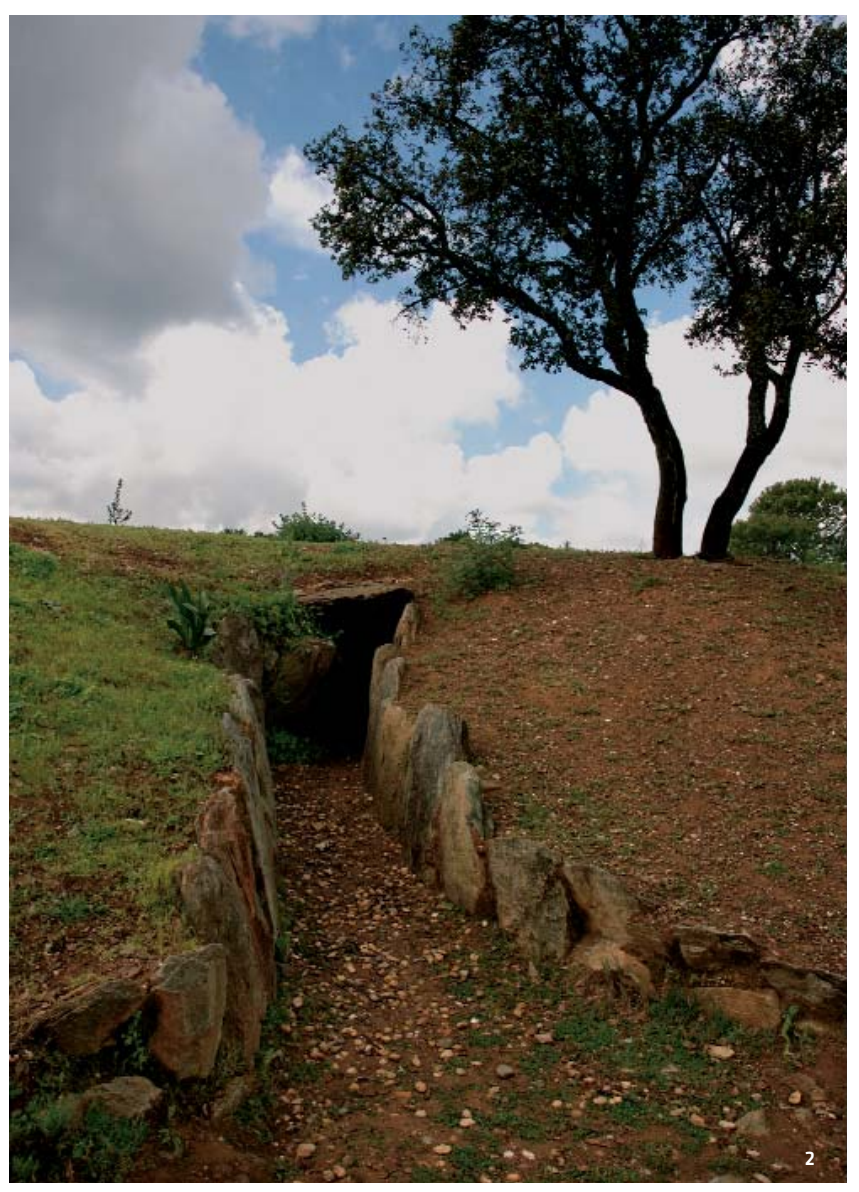

está ausente de las grandes políticas planificadoras en Andalucía a nivel territorial y medio ambiental.

El diseño marco de estas políticas de ordenación del territorio y la protección del medio ambiente tiene su origen a finales de los años ochenta del pasado siglo. El año 1992, por simbólico que parezca, supone el relanzamiento de la política territorial en Europa con la celebración de la Conferencia de Río de Janeiro y la firma del Tratado de la Unión Europea en Maastricht. Tanto el recién acuñado término de "desarrollo sostenible" de la primera, como la cohesión socioeconómica del segundo, van asociados a los dos objetivos recogidos en la Carta Europea de Ordenación del Territorio: la ordenación física del espacio y el desarrollo socioeconómico "equilibrado" de las regiones se expresarán desde ahora bajo los parámetros de la sostenibilidad de Río (BIELZA, 2002) y la cohesión más económica que social de Maastricht.

En este contexto europeo e internacional nace la Ley 1/1994 de Ordenación del Territorio de la Comunidad Autónoma de Andalucía, donde en su preámbulo nos dice que "los objetivos específicos de la Ordenación del Territorio (...) son la articulación territorial interna y con el exterior de la Comunidad Autónoma y la distribución geográfica de las actividades y de los usos del suelo, armonizada con el desarrollo económico, las potencialidades existentes en el territorio y la protección de la naturaleza y del patrimonio histórico; todo ello con el fin de conseguir la plena cohesión e integración de la Comunidad Autónoma, su desarrollo equilibrado y, en definitiva, la mejora de las condiciones de bienestar y calidad de vida de sus habitantes". Dicha ordenación y estructura territorial se llevará a cabo mediante el Plan de Ordenación del Territorio de Andalucía, como marco genérico; y los Planes de Ordenación del Territorio de ámbito subregional para espacios menores que precisen la mejora de su estructura territorial y de la articulación física interna.

Adelantados al momento, la Consejería de Medio Ambiente, embriagada en aquellos entonces por las directivas europeas en el ramo, de golpe y de un solo plumazo, protege el 19 \% de Andalucía con su Ley 2/1989 por la que se aprueba el Inventario de Espacios Naturales Protegidos de Andalucía, y se establecían medidas adicionales para su protección. Nace así la Red de Espacios Naturales de Andalucía (RENPA), la más importante en número y superficie de la Unión Europea con 150 espacios protegidos entre Parques Nacionales (2), Parques Naturales (24), Parques Periurbanos (21), Parajes Naturales (32), Paisajes Protegidos (2), Monumentos Naturales (37), Reservas Naturales (28) y Reservas Naturales Concertadas (4), en los que se encuentran los ecosistemas más representativos del territorio andaluz 4 . En cuanto a la planificación y gestión se crean, con las correspondientes partidas presupuestarias, los Planes de Ordenación de los Recursos Naturales y los Planes Rectores de Uso y Gestión. Se resolvía con esta 
"ley-inventario" la protección, ordenación, uso y gestión de una porción importante de la naturaleza andaluza. La legislación del Territorio asumía, sin rechistar, y dentro del manido término del "desarrollo sostenible" los ámbitos naturales delimitados y protegidos con el fin de concederles una ordenación precisa no sólo de corte territorial, sino también urbanística. Tal es la simbiosis que se establece en estos tiempos entre Medio Ambiente y Ordenación del Territorio que no son pocos los que reivindican la creación de un ministerio o una consejería conjunta siguiendo el modelo dominante en los Länder alemanes, Francia, o Comunidades Autónomas como el País Vasco, Navarra, Canarias o Cantabria (HILDENBRAND, 2004).

Por el contrario, en aquellas mismas fechas, la legislación de Patrimonio Histórico de Andalucía del momento -Ley 1/1991 - si bien perseguía, como se nos dice en su Preámbulo, "una mejor coordinación con la normativa urbanística, de modo que ambas legislaciones se refuercen mutuamente y permitan aprovechar la virtualidad ordenadora de los instrumentos de planificación urbanística. (...); consciente o inconscientemente olvida las obligaciones que tiene la ordenación del territorio con los bienes integrantes del patrimonio histórico, como factor para la estructuración territorial, el desarrollo social y económico de Andalucía. Tal es el caso que las referencias a dicho patrimonio, y lo que es peor, a la tutela del mismo mediante la planificación y ordenación, es casi inexistente. Dichos planes tan solo han tenido en cuenta lo que el positivismo jurídico de nuestras leyes patrimoniales consideran bienes integrantes del patrimonio histórico, porque se les reconoce formalmente el carácter de Bien de Interés Cultural (BIC), o que se encuentran inscritos en el Catálogo General del Patrimonio Histórico Andaluz. Todo aquello que no goza de dicha consideración, en la práctica está relegado a su suerte al carecer de una protección efectiva, y en consecuencia, cualquier planificación territorial o urbanística no tendrían porqué considerarlos bienes singularmente protegidos o tutelados.
En la actualidad, sólo 3623 bienes inmuebles, de los más de 18000 bienes inventariados por la Consejería de Cultura, se encuentran "legalmente" protegidos 5 . Se pone de manifiesto que las políticas de protección y conservación del patrimonio histórico ensayadas en los últimos años han sido poco efectivas, frente a las medidas emprendidas, por ejemplo, por la Consejería de Medio Ambiente y la protección de grandes espacios naturales.

En suma, y para concluir, los bienes culturales, reivindican hoy más que nunca, ante los efectos perversos y perniciosos de la "urbanidad", una mayor presencia en las políticas planificadoras del territorio, el urbanismo, y el medio ambiente. Se hace necesaria una mayor coordinación con aquellas administraciones que tienen competencias directas sobre el terreno, la transformación del suelo, el territorio y el paisaje. A la misma vez, se hace necesario el diálogo permanente entre el conservador de patrimonio histórico y el urbanista; y la participación de arqueólogos en las políticas de ordenación, planificación y ejecución de los planes y programas urbanísticos, territoriales y medioambientales.

\section{Notas}

$\mathbf{1}$ Ley 14/2007 de Patrimonio Histórico de Andalucía.

2 Consultada en 18 de abril de 2008. Consejería de Cultura de la Junta de Andalucía.

3 Así lo dispone en su artículo 4 la Carta Internacional para la Gestión del Patrimonio Arqueológico aprobada en Lausana en 1990.

4 Información obtenida de la web de la Consejería de Medio Ambiente de la Junta de Andalucía: www.juntadeandalucia.es/medioambiente/site/web/

5 Información obtenida a partir del Catálogo General de Patrimonio Histórico Andaluz (fecha de consulta: 18/04/2008); y el Sistema de Información del Patrimonio Histórico de Andalucía (fecha de consulta: 18/04/2008) de la Consejería de Cultura de la Junta de Andalucía.

\section{Bibliografía}

BIELZA DE ORY, V. (2002) Experiencias y retos europeos de la Ordenación del Territorio en relación con la ciudad. En VVAA. Ordenación del territorio, política regional, medio ambiente y urbanismo Gijón (Asturias), $3 a$ de julio de 2001. Madrid: Asociación Interprofesional de Ordenación del Territorio FUNDICOT, 2002, pp. 695 710

HILDENBRAND SCHEID, A. (2004) La política territorial de la Junta de Andalucía (1 982-2002). Análisis de su implementación balance y propuestas para el futuro. En VVAA. El sistema compe- tencial de la Junta de Andalucía y su desarrollo efectivo. Sevilla: Editorial Comares S.L., 2004

LABASSE, J. (1972) L'Organisation de l'Espace. París: Hermann, 1972

PINO RUIZ, A. DEL (2006) El expolio arqueológico en Andalucía Curso sobre protección del patrimonio arqueológico en Andalucía. Sevilla: Junta de Andalucía. Consejería de Cultura, 2006, pp.17-29

PLAN General de Bienes Culturales : PGBC Andalucía 2000. Sevilla: Consejería de Cultura, Junta de Andalucía, 2000
VERDUGO SANTOS, J. (2004) Protección del patrimonio y desarrollo local: nuevas técnicas de tutela y de gestión sobre el territorio. En VVAA. I Congreso Internacional Patrimonio, Desarrollo Rural y Turismo en el Siglo XXI-Osuna 2004. Osuna: Universidad de Sevilla, 2004, pp. 235-252 